\title{
Custos de Produção, Expectativas de Retorno e de Risco do Agronegócio do Alho no Sul do Brasil
}

\author{
Doutorado em Engenharia de Produção pela Universidade Federal de Santa \\ Catarina - UFSC \\ Av Santa Catarina, 228. Fundos. Caçador/SC. CEP: 89.500-000 \\ E-mail:kreuz@epagri.rct-sc.br
}

\begin{abstract}
Alceu Souza
Doutorado em Administração pela Escola de Administração de Empresas de São

Paulo - EAESP/FGV

Rua 24 de Maio 980. Apto 203. Curitiba/PR. CEP: 80230-060

E-mail: alceusouza@bsi.net.br
\end{abstract}

\section{RESUMO}

Este artigo analisa os custos de produção, as expectativas de retorno e de risco associadas ao agronegócio do alho para três níveis de produtividade (8, 10 e 12 toneladas/ha) na região sul do país. Detalham-se os investimentos, os custos de produção, a rentabilidade e os riscos inerentes a esse agronegócio. A metodologia utilizada para a análise de viabilidade consiste na geração de dois conjuntos de indicadores. O primeiro conjunto (Valor Presente Líquido, Valor Presente Líquido Anualizado, Índice Benefício/Custo e Retorno Adicional do Investimento) objetiva melhorar a percepção do retorno, enquanto o segundo conjunto (Índice TMA/TIR, Índice Pay-back/N, Risco de Gestão, Risco do Negócio e Grau de Comprometimento da Receita) objetiva melhorar a percepção do risco. Os resultados sinalizam para rentabilidade expressiva e risco médio para os três níveis de produtividade. O melhor desempenho ocorre com o maior nível de produtividade (12 t/ha) que apresentou rentabilidade de $45,39 \%$ ao ano além, daquela que seria obtida com a aplicação do capital de investimento a $12 \%$ ao ano.

Palavras-chave: Agronegócio do alho. Rentabilidade de agronegócios. Allium sativum.

\section{Production costs, risks and return expectations of the garlic agribusiness in the South of Brazil}

\section{ABSTRACT}

This article analyzes the production costs, the risks and return expectations associates to the garlic agribusiness for three levels of productivity (8, 10 and 12 ton/ha) in the south region of Brazil. The investments, production costs, yields and 
risks are detailed. The methodology used for the viability analysis consists of the generation of two sets of indicators. The first set (Net Present Value, Yearly Present Value, Benefit/Cost Ratio and Additional Return on the Investment) objectives to improve the perception of the return, while the second set (TMA/TIR Ratio, Payback/N Ratio, Management Risk, Business Risk and \% Break-even Point) objectives to improve the perception of the risk. The results showed an expressive yield and average risk for the three levels of productivity. Optimum performance occurs with the biggest level of productivity (12 t/ha) that presented yield of $45,39 \% /$ year beyond that would be gotten with the application of the investment capital at $12 \% / y e a r$.

Key words: Garlic agribusiness. Risk and return indicators. Allium sativum.

\section{INTRODUÇÃO}

A produção brasileira de alho, embora pouco expressiva (com apenas $1 \%$ de participação no volume total dos países produtores), está em oitavo lugar no ranking mundial (Vieira, 2004). O alho é uma hortaliça cultivada, na sua grande maioria, por pequenos e médios agricultores e utiliza mão-de-obra de forma intensiva. Além disto, é uma cultura altamente tecnificada, usando os mais modernos insumos disponíveis no mercado (Kreuz et al., 1997). A melhoria da produtividade tem sido alcançada por investimentos em pesquisa $e$ desenvolvimento realizados por institutos de pesquisas agropecuárias e também por universidades. O repasse dos resultados dessas pesquisas aos alhicultores tem ajudado a viabilizar esse agronegócio. A possibilidade de escolha do nível de produtividade ( 8,10 e 12 t/ha) é um dos resultados imediatos dos investimentos em pesquisa e desenvolvimento.

Atualmente, a produção brasileira de alho é insuficiente para atender a demanda nacional. Para complementar o consumo, o país importa alho da Argentina e do Chile no primeiro semestre do ano e da Espanha e da China no segundo semestre. Importante aspecto relativo à concorrência externa, que o setor nacional enfrenta, diz respeito à China. Com o seu ingresso na OMC (Organização Mundial do Comércio), as medidas de restrição às importações de alhos chineses tomadas pelo Brasil não são mais permitidas. A China é o maior produtor mundial 
de alho com cerca de $55,8 \%$ da área total plantada e $71,2 \%$ da produção que está estimada em 8,8 milhões de toneladas (Vieira, 2004). A Tabela 1, a seguir, apresenta algumas estatísticas interessantes sobre esse agronegócio.

Tabela 1: Área plantada, produção e rendimento médio no mundo e nos principais países

\begin{tabular}{|c|c|c|c|c|c|c|c|c|c|}
\hline \multirow{3}{*}{ PAÍS } & \multicolumn{3}{|c|}{ ÁREA PLANTADA } & \multicolumn{3}{|c|}{ PRODUÇÃ̃O } & \multicolumn{3}{|c|}{$\begin{array}{l}\text { PRODUTIVIDADE } \\
\end{array}$} \\
\hline & & 1000 ha) & & & $(1000 t)$ & & & $(\mathrm{t} / \mathrm{ha})$ & \\
\hline & $01 / 02$ & $02 / 03$ & $03 / 04$ & $01 / 02$ & $02 / 03$ & $03 / 04$ & $01 / 02$ & $02 / 03$ & $03 / 04$ \\
\hline Mundo & $1.092,5$ & $1.126,3$ & $1.132,1$ & $11.445,5$ & $12.182,3$ & $12.407,4$ & 10,47 & 10,81 & 10,95 \\
\hline Brasil & 14,3 & 15,6 & 15,0 & 101,1 & 114,1 & 122,1 & 7,10 & 7,32 & 8,17 \\
\hline China & 584,9 & 627,1 & 632,1 & $7.894,1$ & $8.680,0$ & $8.830,0$ & 13,49 & 13,84 & 13,96 \\
\hline Egito & 9,3 & 9,3 & 9,3 & 215,4 & 216,0 & 216,0 & 23,16 & 23,22 & 23,22 \\
\hline Estados Unidos & 14,3 & 13,3 & 13,5 & 266,6 & 256,3 & 260,0 & 18,64 & 19,31 & 19,26 \\
\hline
\end{tabular}

Atualmente, o Rio grande do Sul é o maior produtor de alho (28,4 mil t). Os estados do Rio grande do Sul, Santa Catarina, Minas Gerais, Goiás e Bahia são responsáveis por cerca de 90\% da produção nacional (ICEPA, 2003). O aumento da produção de alho está acontecendo pelo uso mais intenso de tecnologia resultando em diferentes níveis de produtividade por hectare, do que pela expansão da área plantada.

\subsection{Aspectos da competição entre regiões e países produtores}

Com referência ao agronegócio do alho brasileiro, pode-se destacar cinco regiões produtoras que competem entre si, sendo três no Brasil, além da Argentina e da China. No Brasil destacam-se as regiões produtoras do Rio Grande do Sul, representada pelo município de São Marcos, de Santa Catarina, cujo principal município produtor é Curitibanos e a região do cerrado brasileiro, envolvendo os estados de Goiás e Minas Gerais, cujo principal município produtor é São Gotardo, MG. A Tabela 2, a seguir, mostra que apesar da produção brasileira de alho ser insuficiente para atender a demanda nacional, a área plantada não está sendo aumentada e que o aumento de produtividade não é suficiente para compensar a diminuição dessa área. 
Custos de Produção, Expectativas de Retorno e de Risco do Agronegócio do Alho no Sul do

Brasil

Carlos Leomar Kreuz, Alceu Souza

Tabela 2. Área Plantada, produção e produtividade de alho no Brasil

\begin{tabular}{lrrrrr} 
& 2001 & 2002 & 2003 & 2004 & 2005 \\
\hline Àrea plantada (1.000/ha) & 14,35 & 15,58 & 14,94 & 10,36 & 10,35 \\
Produção (1000 t) & 101,92 & 114,14 & 122,13 & 85,31 & 85,35 \\
Produtividade (t/ha) & 7,10 & 7,33 & 8,17 & 8,23 & 8,25 \\
\hline
\end{tabular}

Fonte: http://www.icepa.com.br/produtos/tabproducao/comparativobr.htm Acesso em 10/05/2005.

Segundo a EMBRAPA (2004), a variação regional de produtividade é muito grande, com alguns produtores chegando a produzir mais do que 13t/ha. Fatores como clima e solo concorrem para essa variação, mas a questão está mais relacionada aos cultivares plantados e as técnicas de cultivo.

$\mathrm{Na}$ cultura do alho, chama a atenção o fato de que, além das dificuldades que o setor enfrenta em competir com o alho proveniente da Argentina e da China, existe a competição interna. O Quadro 1 dá um indicativo da competitividade do alho produzido nas diversas regiões brasileiras frente ao alho argentino e chinês. $O$ alho chinês é um alho branco e graúdo que, gradativamente, está conquistando a preferência do mercado em decorrência da boa apresentação, da facilidade de manuseio e do maior tamanho de seus bulbilhos.

O produtor de alho da região sul enfrenta dificuldades para competir com produtores de outros locais. A Argentina e a China, competidores do exterior, possuem pontos fortes em quase todos os fatores-chave, motivo de sérias preocupações para os produtores brasileiros.

Apesar da existência de vários pontos fracos, não se tem observado, até o momento, ações efetivas para superá-los. Particularmente não há ações de marketing que levem o consumidor brasileiro a preferir o alho nacional. As razões para tal, não ocorrer possivelmente estejam associadas ao fato de a produção interna (brasileira) ser insuficiente para o abastecimento do mercado, o que sempre implicou na existência de facilidades para a sua comercialização. Apenas nos momentos de crises, como a atual ameaça que representa a entrada abundante de alho proveniente da China no mercado brasileiro, observa-se alguma 
movimentação na busca de alternativas. Porém, estas raramente ultrapassam ao consagrado uso da força política tentando coibir ou limitar as importações.

\begin{tabular}{|c|c|c|c|c|c|}
\hline & \multicolumn{5}{|c|}{ REGIÕES PRODUTORAS } \\
\hline FATORES CRÍTICOS & 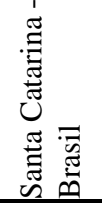 & 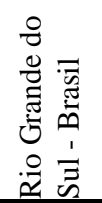 & 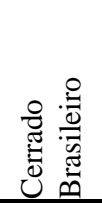 & 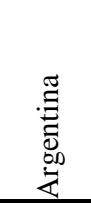 & $\stackrel{\Xi}{\Xi}$ \\
\hline Tributos & Médio & Médio & Forte & Forte & Fraco \\
\hline Legislação p/ mão de obra & Fraco & Forte & Fraco & Fraco & Forte \\
\hline Custo de produção & Fraco & Forte & Fraco & Fraco & Forte \\
\hline Organização da produção & Fraco & Fraco & Forte & Médio & Forte \\
\hline Variedades & Médio & Médio & Médio & Forte & Médio \\
\hline Distribuição do produto & Fraco & Fraco & Forte & Médio & Fraco \\
\hline Apresentação do produto & Fraco & Fraco & Médio & Forte & Forte \\
\hline Suporte de pesquisa & Fraco & Fraco & Fraco & Forte & Forte \\
\hline Clima e solo & Fraco & Fraco & Médio & Forte & Forte \\
\hline
\end{tabular}

Quadro 1. Fatores críticos para a competitividade do alho por região produtora

Fonte: Kreuz (2003)

\subsection{Caracterização do Problema}

As estimativas do IBGE (in www.icepa.com.br acesso em 10/05/2005), para a Região Sul são de 5.274 ha de área plantada, 34.029 t de produção e 6,45 t/ha de produtividade. Observa-se então, que a produtividade da Região Sul é inferior a média nacional. Em decorrência da constatação acima, argumenta-se que o problema pode ser solucionado pelo aumento de produtividade por meio de investimentos em pesquisa.

Como agravante, tem-se o fato de que o alho, na Região Sul do Brasil, é cultivado por pequenos produtores (aquele que mora na propriedade e cultiva uma área de 0,5 a 2,0 ha, usa mão-de-obra familiar e, eventualmente, de terceiros para o plantio e para a colheita) e por médios produtores (aquele que mora no campo ou na cidade, cultivando uma área de até 10 ha, necessita, sempre, de mão-de-obra de terceiros para os principais processos da lavoura). Isso torna mais significativa a necessidade de investimentos em pesquisa e desenvolvimento para melhorar a produtividade. Esses dois tipos de produtores, por razões de limitação de capital, 
dependem dos resultados das pesquisas públicas e também de assistência técnica para melhorar a sua produtividade.

As razões para a dependência externa quanto ao abastecimento de alho remetem ao componente político. Pressões internacionais, oriundas tanta da China como da Argentina, fazem com que, historicamente, seja introduzido alho importado no Brasil em volumes que deixam o preço interno bastante baixo, por vezes quase inviabilizando o seu cultivo em solo brasileiro. Porém, a existência de competição interna (entre diversas regiões brasileiras que produzem alho) e a externa (entre diversos países), às quais a cultura está submetida, exigiu um alto nível de especialização por parte dos técnicos e produtores envolvidos. O fato dos técnicos e produtores terem buscado no desenvolvimento do componente tecnológico a solução dos entraves do setor explica a sobrevivência deste agronegócio nacional (Kreuz, 2003). Particularmente, várias tecnologias desenvolvidas podem ser citadas: aumento na densidade de plantio (Mueller et al., 1998); ampliação do peso do bulbilho semente (Mueller et al., 1998); uso de bulbilhos livre de viroses (Epagril, 2002); controle de doenças (Becker, 2004), entre outras.

A preocupação com a rentabilidade do agronegócio alho tem se traduzido em vários estudos. Já em 1988, Kreuz (1988) buscava verificar o comportamento dos preços do alho e a sua interferência no lucro. Mais tarde, em 1995, Kreuz et al. (1995) procuraram mostrar a importância da adoção de tecnologia no agronegócio e o impacto disto no lucro. Mais recentemente, os estudos se voltaram a verificar a questão do retorno sobre o investimento no agronegócio, bem como a importância de estratégias de liderança em custos e arranjos produtivos (Kreuz et al., 2003; 2004).

No momento as preocupações dos produtores envolvidos com o agronegócio do alho estão voltadas para a questão da rentabilidade dos investimentos em tecnologia. Apesar de estudos mostrarem ser significativa a rentabilidade da cultura (Kreuz, 2003; Kreuz et al., 2003; 2004), a preocupação com a rentabilidade do componente tecnológico é procedente principalmente por estudos conduzidos em outros agronegócios mostrarem que a rentabilidade do capital se mantém à medida 
que os investimentos em tecnologia crescem. A adoção de tecnologia fica mais condicionada a não existência de escassez de capital, do que puramente uma questão de aumento de produtividade ou qualidade (Kreuz, 2002; Kreuz et al., 2002b). A preocupação com rentabilidade da tecnologia adotada remete para a questão da produtividade, havendo uma relação direta entre ambas. A relação entre o nível de tecnologia e a produtividade já se tornou voz corrente, onde os vendedores de insumos, técnicos e produtores se referem ao nível de tecnologia como sendo baixo, médio ou alto, sendo a palavra 'tecnologia' usada como sinônimo de produtividade.

A contribuição deste estudo está em mostrar a importância do investimento em tecnologia para melhorar o resultado financeiro do agronegócio do alho.

\subsection{Objetivo}

O presente estudo tem por objetivo analisar o impacto provocado pelo uso de mais intensificação tecnológica e níveis de produtividade (8, 10 e 12 toneladas). Os parâmetros de custos, produção e produtividade são específicos da Região Sul do Brasil. Os resultados deste estudo podem ser utilizados de duas maneiras distintas: orientar a estratégia de produção e, principalmente, informar ao empresário do setor sobre a rentabilidade e os riscos associados a esse agronegócio.

\section{FUNDAMENTAÇÃO TEÓRICA}

Por ser uma atividade de ciclo operacional longo, envolvendo em torno de treze meses entre os investimentos iniciais e o recebimento das vendas, a avaliação do resultado econômico requer o uso de métodos de análise de investimentos. A metodologia de análise seguirá a proposição de Souza e Clemente (2004). A vantagem dessa abordagem em relação a abordagem clássica (Gitman, 2004; Ross et al., 2004) ou a Teoria das Opções Reais (Copeland et al., 2001) consiste em não expressar o risco por meio de um spread sobre a taxa de desconto. 
A metodologia de Souza e Clemente (2004), também se baseia no fluxo de caixa descontado e consiste em gerar dois conjuntos de indicadores. O primeiro conjunto (Valor Presente Líquido, Valor Presente Líquido Atualizado, Índice Benefício/Custo e Retorno Adicional do Investimento) objetiva melhorar a percepção do retorno, enquanto o segundo conjunto (Índice TMA/TIR, Índice Payback/N, Risco de Gestão, Risco do Negócio e Grau de Comprometimento da Receita) objetiva melhorar a percepção do risco. O tratamento teórico desses indicadores, bem como as fórmulas de cálculo estão disponíveis em vários textos, como em Souza et al. (2002), Souza e Clemente (2004), e Kreuz et al. (2004) e, por essa razão, não será aqui apresentado.

\subsection{Taxa mínima de atratividade (TMA)}

Souza e Clemente (2004) propõem que se use como Taxa de Mínima Atratividade (TMA) a melhor taxa, com baixo grau de risco, disponível para aplicação do capital em análise, e que essa escolha seja compatível com o perfil do investidor. Dessa forma, a rentabilidade obtida considerará como ganho apenas o excedente sobre aquilo que já se tem, isto é, o que será obtido além da aplicação do capital a TMA (12\% ao ano). Esse conceito, desde há muito é defendido pelos economistas e denomina-se custo de oportunidade líquido, isto é, o ganho depois de expurgado aquilo que já se teria em outra alternativa de investimento concorrente. Assim, a rentabilidade do projeto pode ser confrontada com a percepção do risco obtida por meio de outro conjunto de indicadores.

\subsection{Indicadores de viabilidade}

Em artigo recente, Mackinsey et al. (2005) reapresentam as deficiências da TIR como medida de rentabilidade. Neste mesmo artigo estes autores advogam o uso da TIRM (TIR modificada) para expressar a rentabilidade do projeto. Souza e Clemente (2004) argumentam que a rentabilidade do projeto é mais bem representada pelo indicador ROIA (Retorno adicional decorrente do Investimento realizado) que tem a vantagem de expurgar o efeito cruzado da TMA. O Indicador 
ROIA é superior a TIRM porquanto expurga o efeito do spread de risco na taxa de desconto e também o custo de oportunidade, já apresentando o retorno líquido que deve ser confrontado com o risco. Também argumentam que para fluxos de caixa construídos como o valor médio ou mais provável para os custos e receitas, a avaliação do risco seja analisada após a geração dos indicadores de retorno.

Dado que tanto a TMA como a TIR dependem de fatores sistêmicos e conjunturais, é plausível que se interpretem as mesmas como variáveis aleatórias. Dessa forma, Souza e Clemente (2004) argumentam que o risco financeiro de um projeto de investimento (probabilidade de se ganhar mais aplicando na TMA do que no projeto de investimento) pode ser medido pela probabilidade da TIR ser menor do que a TMA, quando as distribuições de probabilidade das mesmas forem conhecidas. Contudo, mesmo não se conhecendo as distribuições de probabilidades, pode-se interpretar a proximidade da TIR em relação a TMA como uma medida de risco. Por essa razão a TIR, ao contrário da metodologia tradicional de análise de projetos, neste artigo está classificada como indicador de risco.

Também, na metodologia de Souza e Clemente (2004) o pay-back descontado é interpretado como um indicador de risco. Ao relacionar o pay-back com a vida útil do projeto $(\mathrm{N})$ melhora-se a percepção do risco (escala de 0 a 1 ) quanto à recuperação do capital investido. Os autores alertam, ainda, que o payback seja interpretado à luz das características do negócio.

Sugere-se, também, que se utilize a opinião de especialistas (Método Delphi) para inferir dois outros tipos de risco: Risco de Gestão e Risco de Negócio. O Risco de Gestão está associado ao grau de sucesso em empreendimentos similares, a competência técnica em produção e comercialização (incluindo-se aí a motivação para a inovação) e a saúde financeira do grupo em análise. O Risco de Negócio está associado a fatores não controláveis que afetam os agronegócios, tais como o surgimento de barreiras alfandegárias, aspectos fitossanitários, variações além do limite nas condições climatológicas na época de plantio e de colheita e, principalmente, preços de mercados não competitivos em função de super oferta ou falta de qualidade do produto. 


\section{MATERIAIS E MÉTODOS}

Trata-se, segundo Silva e Menezes (2001), de uma pesquisa aplicada quanto à natureza do fenômeno (gera conhecimentos para aplicação prática); quantitativa quanto à abordagem metodológica (relações entre produção, custos e receitas são expressas em números para o plantio de um hectare de alho); descritiva e explicativa quanto aos objetivos (descreve e explica a relação entre as variáveis representativas da produção, custos e receitas) e de levantamento, do ponto de vista dos procedimentos técnicos de coleta de dados (foram realizadas entrevistas e pesquisa de campo). As informações necessárias para suportar tal estudo foram obtidas em consultas diretas feitas a pesquisadores da área, extensionistas rurais, lideranças do setor e a produtores de alho. Essas informações foram complementadas com dados secundários levantados junto a trabalhos anteriores realizados na região, tais como os de ICEPA/SC (2003), Epagri (2002) e Kreuz (2003).

A abrangência deste estudo limitou-se as regiões produtoras de alho do Rio Grande do Sul (representada pelo município de São Marcos) e de Santa Catarina (cujo principal município produtor é o de Curitibanos).

\subsection{Metodologia}

A metodologia consiste em aplicar os indicadores propostos por Souza e Clemente (2004) para avaliar a exploração hipotética de 1 hectare de cultivo de alho para cada um dos níveis de produtividade ( 8,10 e $12 \mathrm{t} / \mathrm{ha})$. As variáveis de análise para os diferentes níveis de produtividade foram: investimentos, custos de produção, escala de produção e preços de mercado.

\subsection{Preparação dos dados}

Os coeficientes para a implantação de 1 ha se referem a áreas onde tradicionalmente já se planta alho e não há necessidade de destoca ou queimada. $\mathrm{A}$ Tabela 3, a seguir, apresenta os coeficientes técnicos e os resultados monetários 
associados à implantação de 1 hectare de alho nos três níveis de produtividade em estudo.

Tabela 3. Coeficientes técnicos para o plantio de 1 ha de alho em três níveis de produtividade

\begin{tabular}{|c|c|c|c|c|c|c|c|}
\hline \multirow{2}{*}{ Descrição } & \multirow[t]{2}{*}{ R\$/Unid } & \multicolumn{2}{|c|}{$8 \mathrm{t} / \mathrm{ha}$} & \multicolumn{2}{|c|}{$10 \mathrm{t} / \mathrm{ha}$} & \multicolumn{2}{|c|}{$12 \mathrm{t} / \mathrm{ha}$} \\
\hline & & Quant & $\mathbf{R} \$ \mathbf{h a}$ & Quant & $\mathbf{R} \$ \mathbf{h a}$ & Quant & $\mathbf{R} \$ \mathbf{h a}$ \\
\hline Fungicidas (l ou kg) & & 22,50 & 642,00 & 30,50 & 992,50 & 49,00 & $1.919,00$ \\
\hline Dithane/manzate & 25,00 & 18,00 & 450,00 & 22,00 & 550,00 & 30,00 & 750,00 \\
\hline Score & 235,00 & 0,00 & 0,00 & 0,50 & 117,50 & 2,00 & 470,00 \\
\hline Bravonil ultrex & 54,00 & 1,50 & 81,00 & 3,00 & 162,00 & 8,00 & 432,00 \\
\hline Captan & 26,00 & 2,00 & 52,00 & 4,00 & 104,00 & 8,00 & 208,00 \\
\hline Derosal & 59,00 & 1,00 & 59,00 & 1,00 & 59,00 & 1,00 & 59,00 \\
\hline Inseticidas/Nematicidas (l) & & 3,00 & 128,00 & 6,00 & 317,00 & 9,00 & 506,00 \\
\hline Vertimec & 180,00 & 0,00 & 0,00 & 0,50 & 90,00 & 1,00 & 180,00 \\
\hline Decis & 58,00 & 1,00 & 58,00 & 1,50 & 87,00 & 2,00 & 116,00 \\
\hline Sumithion & 35,00 & 2,00 & 70,00 & 4,00 & 140,00 & 6,00 & 210,00 \\
\hline Herbicidas (l) & & 3,00 & 288,00 & 6,00 & 462,00 & 8,00 & 640,00 \\
\hline Ronstar & 58,00 & 0,00 & 0,00 & 3,00 & 174,00 & 4,00 & 232,00 \\
\hline Totril & 120,00 & 2,00 & 240,00 & 2,00 & 240,00 & 3,00 & 360,00 \\
\hline Poast & 48,00 & 1,00 & 48,00 & 1,00 & 48,00 & 1,00 & 48,00 \\
\hline Adubos (t) & & 0,85 & 820,00 & 11,80 & $2.528,00$ & 17,50 & $3.604,00$ \\
\hline Esterco aves & 70,00 & 0,00 & 0,00 & 10,00 & 700,00 & 15,00 & $1.050,00$ \\
\hline Adubo $3-30-15$ & 960,00 & 0,80 & 768,00 & 1,50 & $1.440,00$ & 2,00 & $1.920,00$ \\
\hline Uréia & 1040,00 & 0,05 & 52,00 & 0,10 & 104,00 & 0,20 & 208,00 \\
\hline Nitrato de Cálcio & 1420,00 & 0,00 & 0,00 & 0,20 & 284,00 & 0,30 & 426,00 \\
\hline Semente $(t)$ & & 0,70 & $1.890,00$ & 1,20 & $3.240,00$ & 1,50 & $4.050,00$ \\
\hline Alho-semente & 2700,00 & 0,70 & $1.890,00$ & 1,20 & $3.240,00$ & 1,50 & $4.050,00$ \\
\hline Serviços Mecânicos $(\mathbf{h} / \mathbf{m})$ & & 48,70 & 799,20 & 79,83 & $1.358,78$ & 107,00 & $1.859,00$ \\
\hline Aração e Gradagem & 15,00 & 10,00 & 150,00 & 10,00 & 150,00 & 10,00 & 150,00 \\
\hline Distribuição adubo & 16,00 & 2,70 & 43,20 & 3,33 & 53,28 & 4,00 & 64,00 \\
\hline Aplicação defensivos & 18,00 & 12,00 & 216,00 & 16,00 & 288,00 & 20,00 & 360,00 \\
\hline Construção de Canteiros & 18,00 & 10,00 & 180,00 & 10,00 & 180,00 & 10,00 & 180,00 \\
\hline Irrigação & 20,00 & 0,00 & 0,00 & 16,00 & 320,00 & 32,00 & 640,00 \\
\hline Transporte interno & 15,00 & 10,00 & 150,00 & 12,50 & 187,50 & 15,00 & 225,00 \\
\hline Transporte diaristas & 15,00 & 4,00 & 60,00 & 12,00 & 180,00 & 16,00 & 240,00 \\
\hline Serviços manuais $(\mathbf{h} / \mathbf{h})$ & & $2.062,70$ & $5.156,75$ & $2.551,33$ & $6.378,33$ & $3.200,00$ & $8.000,00$ \\
\hline Adubação & 2,50 & 26,70 & 66,75 & 33,33 & 83,33 & 40,00 & 100,00 \\
\hline Preparo semente & 2,50 & 320,00 & 800,00 & 320,00 & 800,00 & 320,00 & 800,00 \\
\hline Plantio & 2,50 & 300,00 & 750,00 & 350,00 & 875,00 & 400,00 & $1.000,00$ \\
\hline Capina & 2,50 & 200,00 & 500,00 & 200,00 & 500,00 & 200,00 & 500,00 \\
\hline Irrigação & 2,50 & 0,00 & 0,00 & 200,00 & 500,00 & 400,00 & $1.000,00$ \\
\hline Aplicação defensivos & 2,50 & 96,00 & 240,00 & 128,00 & 320,00 & 160,00 & 400,00 \\
\hline Colheita/estaleiramento & 2,50 & 533,33 & $1.333,33$ & 666,67 & $1.666,68$ & 800,00 & $2.000,00$ \\
\hline Toalete & 2,50 & 266,67 & 666,68 & 333,33 & 833,33 & 400,00 & $1.000,00$ \\
\hline Limpeza, embalagem & 2,50 & 320,00 & 800,00 & 320,00 & 800,00 & 480,00 & $1.200,00$ \\
\hline Embalagens & & & 660,00 & & 880,00 & & $1.100,00$ \\
\hline Assistência Técnica & & & 120,00 & & 160,00 & & 180,00 \\
\hline Total & & & $10.503,95$ & & $16.316,61$ & & $21.858,00$ \\
\hline
\end{tabular}

Fonte: dados da pesquisa

\section{PRODUTIVIDADE E CUSTOS DE PRODUÇÃO}

O alho da Região Sul é oriundo de pequenos produtores rurais. Segundo a 
ICEPA (2003), a área média cultivada está estimada em 5 hectares. A Figura 1, a seguir, sumariza o comportamento dos custos em função da densidade. Com o acréscimo na densidade de plantio, altera-se, basicamente, o item serviços, motivado por maiores necessidades de intervenções humanas, particularmente para as atividades de preparo da semente, de colheita e detoalete.

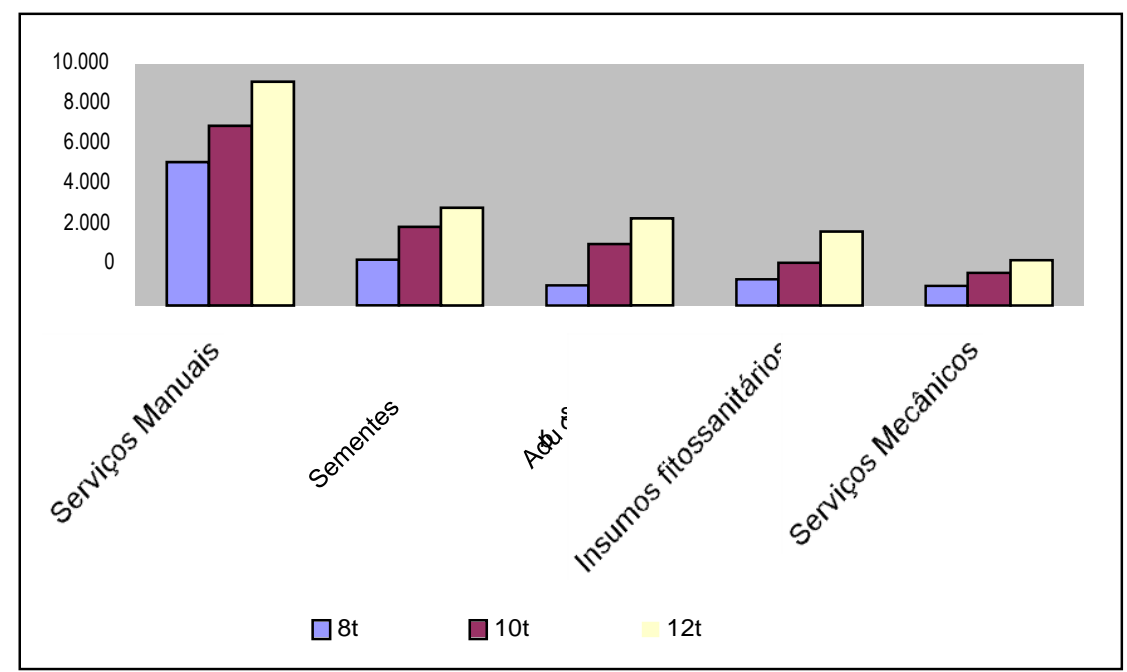

Figura 1. Principais custos de produção por nível de produtividade

Uma análise mais detalhada dos custos de produção revela que a espécie de custos de serviços manuais é a mais representativa nos três níveis de produtividade. A Figura 2, a seguir, apresenta a estrutura do custo de produção para uma densidade $12 \mathrm{t} / \mathrm{ha}$. 


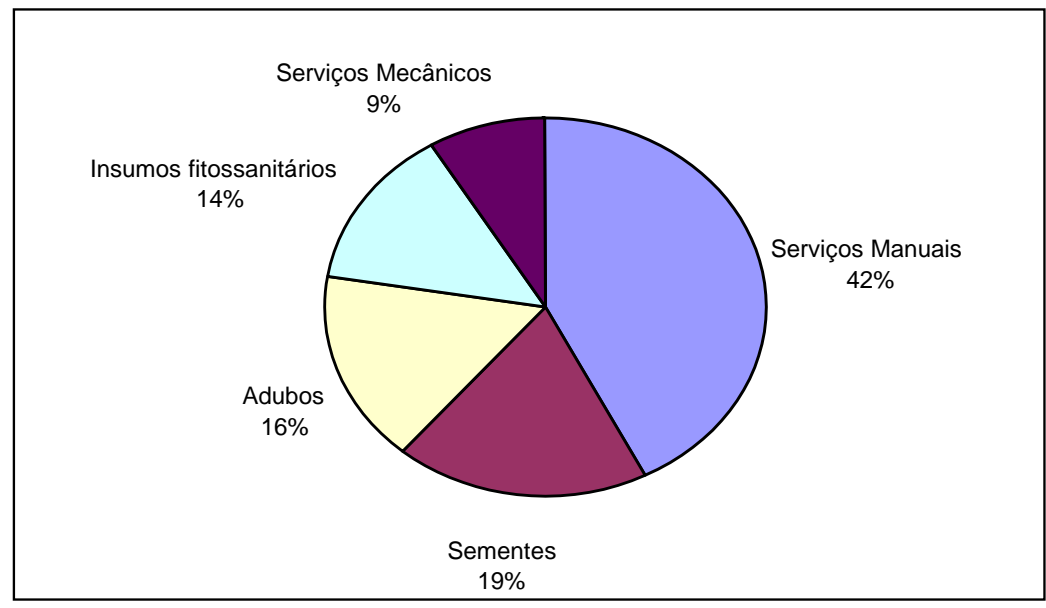

Figura 2: Estrutura de custos de produção do alho (12 t/ha) Fonte: dados de pesquisa

A vantagem da escolha de nível de produtividade maior tende a se manifestar no aumento do valor da produção. A Tabela 4, a seguir, mostra os resultados do valor da produção em função do nível de produtividade. 0 confronto dos custos de produção com a receita esperada é feito por meio do fluxo de caixa descontado, cujos resultados são apresentados a seguir.

Tabela 4. Preço médio de venda e nível de produção nas diferentes classes, jan/jun 2004

\begin{tabular}{|c|c|ccc|}
\hline Classe Alho & Preço R\$ & \multicolumn{3}{|c|}{ Produtividade } \\
& & $8 \mathrm{t} / \mathrm{há}$ & $10 \mathrm{t} / \mathrm{há}$ & $12 \mathrm{t} / \mathrm{há}$ \\
\hline 7 & 3,00 & $0 \%$ & $15 \%$ & $30 \%$ \\
6 & 2,70 & $15 \%$ & $30 \%$ & $45 \%$ \\
5 & 2,20 & $20 \%$ & $30 \%$ & $15 \%$ \\
4 & 1,80 & $30 \%$ & $12 \%$ & $5 \%$ \\
3 & 1,50 & $25 \%$ & $5 \%$ & $2,50 \%$ \\
Industrial & 0,80 & $10 \%$ & $8 \%$ & $\mathbf{2 , 5 0 \%}$ \\
\hline Preço médio & & $\mathbf{2 , 4 5}$ & $\mathbf{2 , 8 4}$ & $\mathbf{3 , 1 1}$ \\
Valor Produção & & $\mathbf{1 4 . 7 2 0 , 0 0}$ & $\mathbf{2 2 . 7 5 0 , 0 0}$ & $\mathbf{3 1 . 1 1 0 , 0 0}$ \\
\hline
\end{tabular}

Fonte: Kreuz, C.L. \& Lucini, M.A. (2005)

Custo de produção da safra plantada em junho/julho de 2004.

Preços praticados no primeiro semestre de 2004. 


\subsection{Preparação do Fluxo de Caixa}

O valor da terra, patrimônio permanente do proprietário rural, não está incluído no fluxo de caixa pelas seguintes razões:

- o valor atribuído a terra não representa efetivamente desembolso;

- mesmo tendo valor de mercado, o proprietário rural não considera a possibilidade de vendê-la;

- a terra, se devidamente manejada, não se deprecia e, se o seu valor fosse considerado como investimento, ao final do projeto a terra estaria disponível e apresentaria valor, na pior das hipóteses, equivalente ao que apresentava no início.

O custo de oportunidade da terra, representado pelo seu uso alternativo, pode ser interpretado como uma outra opção de investimento que deve ser confrontado com o retorno e o risco de investir na melhor alternativa de cultivo de 1 ha de alho.

As informações contidas nas Tabela 1 e 3 permitiram a construção dos fluxos de caixa (Tabela 5) para os três níveis de produtividade para a exploração de 1 hectare de alho. 
Custos de Produção, Expectativas de Retorno e de Risco do Agronegócio do Alho no Sul do

Brasil

Carlos Leomar Kreuz, Alceu Souza

Tabela 5. Custo, receita e fluxo de caixa para a exploração de 1 ha do agronegócio do alho para três níveis de produtividade e preços de junho de 2004

\begin{tabular}{l|rrrrrrrrr}
\multicolumn{3}{c}{} & \multicolumn{3}{c}{ Custos } & \multicolumn{3}{c}{ Receitas } & \multicolumn{3}{c}{ Fluxo de Caixa } \\
\hline maves & $8 \mathrm{t} / \mathrm{ha}$ & $10 \mathrm{t} / \mathrm{ha}$ & $12 \mathrm{t} / \mathrm{ha}$ & $8 \mathrm{t} / \mathrm{ha}$ & $10 \mathrm{t} / \mathrm{ha}$ & $12 \mathrm{t} / \mathrm{ha}$ & $8 \mathrm{t} / \mathrm{ha}$ & $10 \mathrm{t} / \mathrm{ha}$ & $12 \mathrm{t} / \mathrm{ha}$ \\
\hline mar/04 & 1.974 & 3.382 & 4.218 & & & & -1.974 & -3.382 & -4.218 \\
abr/04 & 1.642 & 3.622 & 4.922 & & & -1.642 & -3.622 & -4.922 \\
mai/04 & 994 & 1.640 & 2.824 & & & & -994 & -1.640 & -2.824 \\
jun/04 & 1.664 & 2.033 & 2.363 & & & & -1.664 & -2.033 & -2.363 \\
jul/04 & 478 & 760 & 1.003 & & & & -478 & -760 & -1.003 \\
ago/04 & 228 & 510 & 753 & & & & -228 & -510 & -753 \\
set/04 & 478 & 760 & 1.003 & & & & -478 & -760 & -1.003 \\
out/04 & 228 & 510 & 753 & & & & -228 & -510 & -753 \\
nov/04 & 559 & 750 & 901 & & & & -559 & -750 & -901 \\
dez/04 & 529 & 697 & 835 & & & & -529 & -697 & -835 \\
jan/05 & 749 & 991 & 1.202 & & & & -749 & -991 & -1.202 \\
fev/05 & 793 & 979 & 1.268 & 4.907 & 7.583 & 10.370 & 4.114 & 6.604 & 9.102 \\
mar/05 & 793 & 979 & 1.268 & 4.907 & 7.583 & 10.370 & 4.114 & 6.604 & 9.102 \\
abr/05 & 573 & 686 & 902 & 4.907 & 7.583 & 10.370 & 4.334 & 6.897 & 9.469 \\
\hline
\end{tabular}

Fonte: dados da pesquisa

\section{RESULTADOS}

O Quadro 2, a seguir, apresenta os resultados dos indicadores de retorno (Valor Presente Líquido, Valor Presente Líquido Anualizado, Índice Benefício/Custo e Retorno Adicional do Investimento) e de risco (Relação TMA/TIR, Relação Payback/N, Risco de Gestão e Risco do Negócio) para a exploração de 1 ha do agronegócio do alho para três níveis de produtividade (8, 10 e 12 t/ha) na Região Sul do Brasil. Os indicadores apontam para rentabilidade expressiva e risco médio com tendência para alto nesse agronegócio.

\subsection{Interpretação e análise dos indicadores}

Em função de ter apresentado maior rentabilidade, tomar-se-á o nível de produtividade de $12 \mathrm{t} /$ ha como base para a interpretação dos indicadores e, mutadis mutandis, essa mesma interpretação será válida para as demais opções de investimentos. 
Carlos Leomar Kreuz, Alceu Souza

\begin{tabular}{|c|c|c|c|c|}
\hline & & $8 \mathrm{t} / \mathrm{ha}$ & $10 \mathrm{t} / \mathrm{ha}$ & $12 \mathrm{t} / \mathrm{ha}$ \\
\hline \multirow{7}{*}{$\begin{array}{l}\mathbf{z} \\
z \\
\text { Oo } \\
\text { w }\end{array}$} & Valor Presente do Fluxo de Investimentos & 8.339 & 13.719 & 18.427 \\
\hline & Valor Presente do Fluxo de Benefícios & 11.439 & 20.144 & 27.647 \\
\hline & Valor Presente Líquido & 3.100 & 6.424 & 9.220 \\
\hline & VPL equivalente/mês & 255 & 494 & 709 \\
\hline & Índice Benefício Custo & 1,37 & 1,47 & 1,50 \\
\hline & ROIA Mensal & $2,46 \%$ & $3,00 \%$ & $3,17 \%$ \\
\hline & ROIA Annual & $33,88 \%$ & $42,55 \%$ & $45,43 \%$ \\
\hline \multirow{8}{*}{$\begin{array}{l}\text { O্ } \\
\bar{x}\end{array}$} & Taxa Interna de Retorno ${ }_{\text {Mensal }}$ & $4,56 \%$ & $4,14 \%$ & $4,36 \%$ \\
\hline & Taxa Interna de Retorno Anual & $70,81 \%$ & $62,69 \%$ & $66,96 \%$ \\
\hline & Índice TMA / TIR & 0,21 & 0,23 & 0,22 \\
\hline & Pay-back em mês & 13 & 13 & 13 \\
\hline & Índice Pay-back / N & 1 & 1 & 1 \\
\hline & Risco de Gestão & 0,5 & 0,5 & 0,5 \\
\hline & Risco de Negócios & 0,65 & 0,65 & 0,65 \\
\hline & Grau de Comprometimento da Receita & 0,42 & 0,40 & 0,32 \\
\hline
\end{tabular}

Quadro 2. Indicadores de retorno e de risco para 1 ha de alho para três níveis de produtividade. Fonte: dados da pesquisa

Valor Presente Líquido (VPL) - Ao optar pelo investimento no agronegócio do alho, as expectativas são de que se recupere os investimentos efetuados ( $R \$$ $18.427,00)$; recupere-se também o que se teria auferido se esse capital tivesse sido aplicado no mercado financeiro a $12 \%$ ao ano e, ainda the sobre, em valores monetários de hoje, a importância de $R \$ 9.220,00$ e mais a disponibilidade da terra para iniciar um outro ciclo de cultivo após 13 meses de imobilização. Neste estágio da análise, pode-se dizer, apenas, que entre realizar o empreendimento de explorar 1 hectare desse agronegócio ou usar esse dinheiro para aplicação no mercado financeiro a $12 \%$ ao ano (TMA), a decisão de empreender apresenta ganho maior. A informação do VPL, embora útil, não é suficiente para suportar uma decisão de investimentos por não permitir aquilatar a magnitude do retorno que se está obtendo.

Valor Presente Líquido Equivalente Mensal - Tem a mesma interpretação do VPL e representa o ganho do agronegócio distribuído em valores equivalentes mensais. O VPLmensal desse agronegócio está estimado em R $\$ 709,00 /$ ha além daquilo que seria auferido pela aplicação desse capital a $12 \%$ ao ano. A deficiência comum do VPL e do VPLa, para expressar o retorno do investimento, reside no fato de ambos o expressar em valores monetários absolutos e não em valores relativos, 
como é usual no mercado.

Índice Benefício/Custo (IBC) - O IBC visa, em parte, corrigir a deficiência do VPL e do VPLmensal que é a de expressarem o retorno em valores absolutos. $\mathrm{O}$ IBC é um indicador relativo e mede a expectativa de retorno para cada unidade de capital imobilizada no projeto. Para a exploração de 1 hectare de alho, com nível de produtividade de $12 \mathrm{t}$, a expectativa é obter $R \$ 1,50$ (após 13 meses e em valores monetários de hoje) para cada $R \$ 1,00$ imobilizado hoje. É importante observar que esse é um retorno além daquele que se teria se esse $R \$ 1,00$ tivesse sido aplicado à TMA (12\% ao ano) por 13 meses. O IBC igual a $R \$ 1,50$ também pode ser interpretado como uma rentabilidade adicional de 50\%, em 13 meses, além daquela que o mercado financeiro pagaria (12\% ao ano). O IBC, assim como o VPL, não deve ser usado, isoladamente, para aquilatar a magnitude relativa do ganho por estar expresso em um horizonte de tempo não convencional (13 meses). Uma alternativa de usá-lo para análise, reside em encontrar o seu equivalente anual (ROIAanual).

Retorno adicional decorrente do investimento (ROIAanual) - O ROIAanual, obtido a partir do IBC, representa as expectativas quanto à rentabilidade anual desse agronegócio. É um indicador de mais fácil interpretação porquanto está na mesma unidade de tempo da TMA, isto é, por ano. O ROIA, associado à exploração de 1 ha de alho com nível de produtividade de 12 t, está estimado em $45,39 \%$ ao ano além do que se teria obtido se o capital tivesse sido aplicado no mercado financeiro a $12 \%$ ao ano. Aqui, fica evidente que a rentabilidade desse investimento é expressiva e poder-se-ia pensar que esse patamar de rentabilidade funcionasse como estímulo para a expansão desse agronegócio. Os dados constantes da Tabela 2 contrariam essa linha de raciocínio. Se a rentabilidade alta não está funcionando como atrativo para novos entrantes então a percepção de risco é mais acentuada do que parece.

Taxa interna de retorno (TIR) - A TIR é a taxa que anula o VPL (e, por conseguinte o VPLa também) de um fluxo de caixa. Embora muitos autores a usem como medida de retorno, na metodologia proposta por Souza e Clemente (2004) ela 
é usada como medida de risco. Na verdade, a TIR define o limite para a variação da TMA. Enquanto a TMA (atualmente estimada em 12\% ao ano) permanecer inferior a $\operatorname{TIR}(66,96 \%$ ao ano), as expectativas são de que haja mais ganho em se empreender do que deixar o dinheiro aplicado à TMA (Figura 3). Assim, a proximidade (ou distância) entre a TIR e a TMA pode representar o risco (ou segurança) do projeto. Aqui, o risco está sendo interpretado como a possibilidade de se ganhar mais, deixando o capital aplicado no mercado a $12 \%$ ao ano do que investir na exploração de 1 hectare de cultivo do alho. Esse risco é melhor visualizado pelo Índice TMA/TIR na escala de 0 a 1, na qual 1 representa o risco máximo. O Índice TMA/TIR de 0,22 sinaliza para um risco financeiro muito baixo para esse agronegócio. Considerando apenas este tipo de risco, é visível a segurança da decisão de empreender pois seria necessário que a TMA, atualmente em $12 \%$ ao ano (ou $0,949 \%$ ao mês), se alterasse para $66,96 \%$ ao ano (ou $4,36 \%$ ao mês), para que o mercado financeiro propiciasse o mesmo retorno do agronegócio do alho.

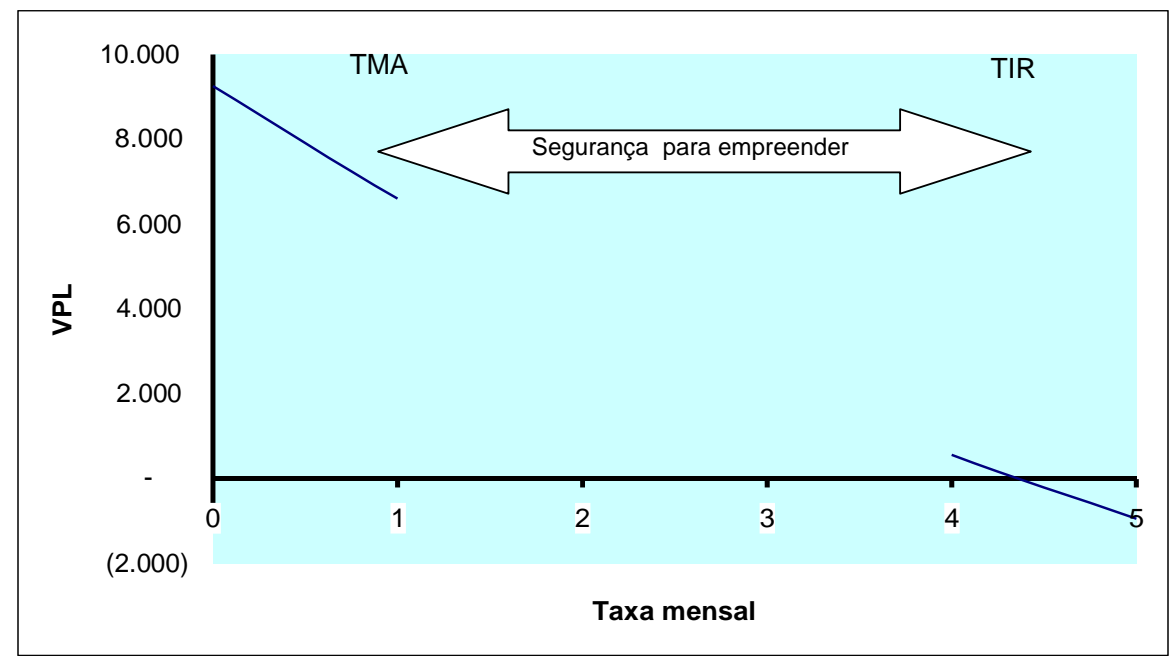

Figura 3. Relação VPL, TMA e TIR para empreender 1 ha de alho com densidade de $12 \mathrm{t}$.

Pay-back descontado - Representa o tempo necessário para a recuperação do investimento. Também pode ser interpretado como uma medida de risco. Quanto maior o período de tempo para recuperar o capital investido, maior o risco do 
projeto. Dadas as características do empreendimento em análise (culturas temporárias), é natural que o pay-back ocorra no penúltimo ou último mês quando ocorre a colheita e o recebimento pela venda da produção. No caso do alho, o payback acontece no último período (13 meses) quando acontece a venda da produção. Para utilizar o Pay-back descontado como medida de risco, recomendase o uso do Índice Pay- backN . O valor de 1 encontrado para o agronegócio do alho sinaliza para um risco alto de não recuperação do capital investido. Se houver qualquer imprevisto com a produção (doenças, problemas climatológicos, etc) ou com a comercialização (preços abaixo do esperado) o capital investido não será recuperado porquanto não existem receitas intermediárias.

Risco de Gestão - O Risco de Gestão está associado às experiências de sucesso e ao conhecimento do processo de produção e de comercialização que o empreendedor tem sobre o assunto. Os produtores de alho da Região Sul são experientes com esse tipo de cultura. Além disso, eles contam com orientação de técnicos do serviço público estadual de pesquisa e de assistência ao produtor rural. Segundo especialistas da EPAGRI-SC, que foram consultados, o risco de má gestão nesse tipo de empreendimento pode ser considerado médio $(0,5)$. A justificativa para esses valores baixos se explica, em parte, pela experiência já acumulada tanto pelo learning by interacting quanto pelo learning by doing na região com esse agronegócio.

Risco do Negócio - Praticamente todo o alho-semente utilizado no Brasil está contaminado com um ou mais patógenos, notadamente vírus (EMBRAPA, 2004). A ocorrência de pragas e doenças é expressiva nas regiões produtoras de alho no sul do país (EPAGRI, 2002). De acordo com Kreuz et al, (1997), a cultura do alho consome anualmente em torno de 100 mil quilogramas de fungicidas, 14 mil litros de inseticidas e 8 mil litros de herbicidas. Acrescente-se a isso as dificuldades que os produtores de alho enfrentam para o controle das pragas (Tripes, Ácaro, Lagarta rosca, Mosca-da-cebola e Traças) e doenças (Nematóides, Podridão branca, Mofo, Podridão seca, Cabeça negra, Ferrugem, Mancha de estenfílio, Queima bacteriana e Viroses). O uso de novas cultivares de alho resistentes 
principalmente às principais doenças depende da pesquisa pública, e não se vislumbra, ao menos no curto prazo, o desenvolvimento de novas cultivares de alho com este propósito. Além disto, são reais as chances de variações acentuadas nos preços. Desta forma, o Risco de Negócio, segundo especialistas da EPAGRI-SC também é considerado médio. Assim, em consenso os técnicos e especialistas da região atribuem um valor de 0,65 para o risco do agronegócio do alho.

Grau de Comprometimento da Receita - O percentual da receita que está comprometido com o pagamento dos custos também pode ser interpretado como uma medida de risco. As informações básicas para o cálculo desse indicador são os custos fixos, o custo variável unitário e o preço médio de venda. A Tabela 5, a seguir, apresenta essas informações. O Grau de Comprometimento da Receita igual a 0,32 significa que $32 \%$ da Receita está comprometida para o pagamento dos custos. Esse indicador mede o risco operacional do empreendimento e significa que a produção mínima necessária para cobrir todos os custos é baixa, isto é, cerca de 4t./ha.

\subsection{Síntese da análise dos indicadores}

Como afirmado anteriormente e comparando-se com os resultados de outros estudos na região (Kreuz et al., 2003; Kreuz, 2003; Souza et al., 2004), a análise dos indicadores de viabilidade do cultivo de 1 hectare de alho apresenta rentabilidade expressiva, ou seja, $45,39 \%$ ao ano acima dos $12 \%$ que seria auferido pela decisão de não empreender. O risco financeiro, isto é, a chance de se ganhar mais dinheiro no mercado financeiro do que na atividade de empreender, fica descartada pela distância entre a TIR e a TMA. O risco de não recuperação do capital investido é alto pelas próprias características do fluxo de caixa desse tipo de agronegócio (Receitas só ao final do período). O Risco de Gestão, apesar da competência na gestão da produção, é considerado médio. O Risco de Negócio é considerado médio/alto devido as incertezas quanto a qualidade final do produto, volume de produção esperado e preços de mercado à época da comercialização. 
Custos de Produção, Expectativas de Retorno e de Risco do Agronegócio do Alho no Sul do

Carlos Leomar Kreuz, Alceu Souza

Tabela 5. Ponto de Equilíbrio e Grau de Comprometimento da Receita

\begin{tabular}{lrrr}
\hline Tonelada/ha & 8 & 10 & 12 \\
\hline Custo Variável / t & 1.313 & 1.632 & 1.822 \\
Custo Variável/Kg & 1,31 & 1,63 & 1,82 \\
Custo Fixo & 1.790 & 2.580 & 2.998 \\
Preço de Venda / t & 1,84 & 2,28 & 2,59 \\
Receita Total & 14.720 & 22.750 & 31.110 \\
Ponto de Equilíbrio & 3.397 & 4.010 & 3.888 \\
Ponto de Equilíbrio em \$ & 6.250 & 9.123 & 10.081 \\
GCR & 0,42 & 0,40 & 0,32 \\
\hline
\end{tabular}

A Figura, 4, a seguir, apresenta a percepção de risco para o alho com nível de produtividade de 12t/ha. Todos os indicadores de risco estão apresentados em uma escala de 0 a 1 onde 1 representa o risco máximo.

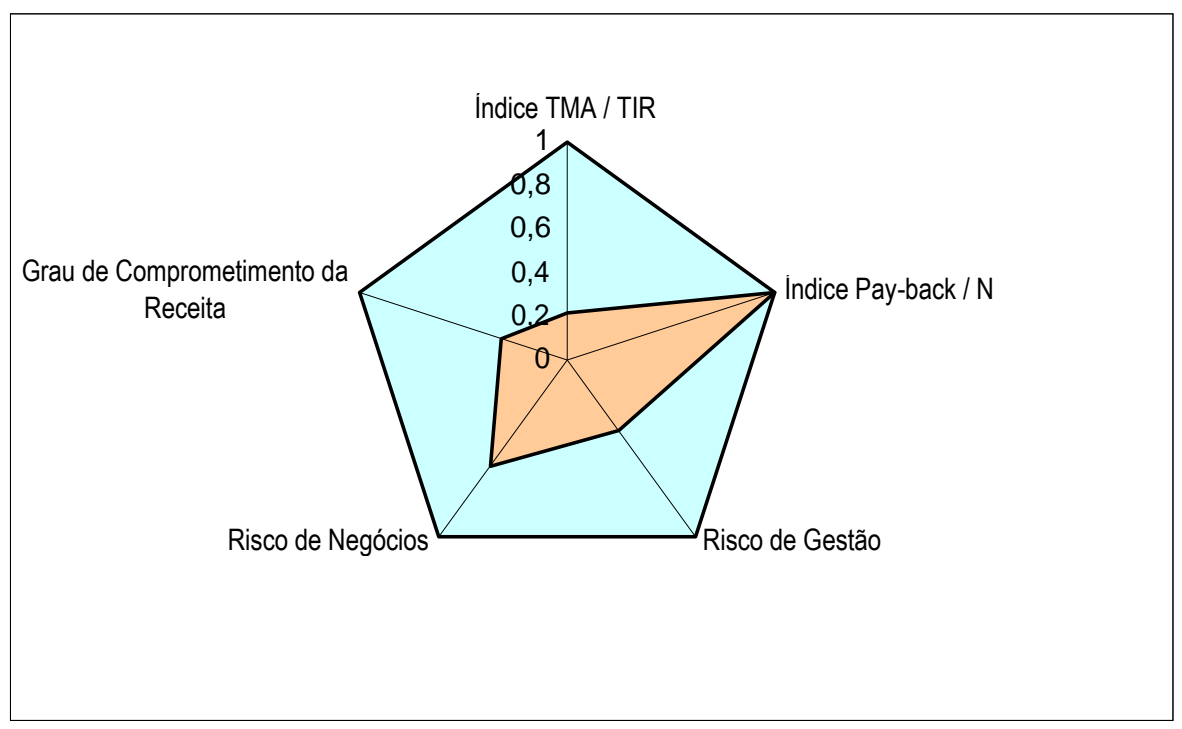

Figura 4. Riscos percebidos para a exploração de 1 ha de alho com 12 t de produtividade.

\section{CONCLUSÕES}

A rentabilidade (ROIA) do agronegócio do alho é expressiva e melhora com a intensificação tecnológica. Dado os níveis de adoção de tecnologia que hoje se verifica junto aos produtores, o uso de práticas de produção moderna é 
recomendado uma vez que os retornos financeiros que as mesmas possibilitam compensam os desembolsos necessários para o seu uso.

A produtividade tem melhorado, mas não tem dado saltos significativos que sustentem o consumo interno.

Apesar da rentabilidade expressiva e da produção nacional ser inferior a demanda, a área plantada não tem aumentado.

Se a rentabilidade é alta e existe demanda, o fator que está inibindo a expansão da área plantada (por produtores atuais ou por novos entrantes) pode ser atribuído ao risco do negócio que é alto. A percepção dos produtores quanto ao risco é fortemente influenciada pelas oscilações de preço decorrente de importações, principalmente do alho chinês. O fracasso financeiro das últimas safras, decorrente do excesso de alho importado, ainda estão impactando fortemente o risco percebido.

Em economias de mercado globalizados não há como impedir, sem retaliações, as importações. Dessa forma, a viabilidade do alho brasileiro, principalmente da Região Sul, depende de duas estratégias básicas: 1) mais pesquisas e desenvolvimento para aumentar a produtividade e 2) optar por uma diferenciação de produtos investindo no alho roxo nobre que já tem a preferência do consumidor brasileiro.

\section{REFERÊNCIAS}

COPELAND, T. et al. 2001. Opções reais: um novo paradigma para reinventar a avaliação de investimentos. Rio de Janeiro, Campus, 368 p.

DAY, G. 1999. Manutenção da vantagem com petitiva: criação e sustentação das vantagens em ambientes competitivos dinâmicos. In: G.S. DAY e D.J. REI BSTEI N, A dinâmica da estratégia competitiva. Rio de Janeiro, Campus, 462 p.

EMBRAPA. 2004. Boletim de pesquisa e desenvolvimento - controle de qualidade de produção de alho-semente da cultivar amarante por meio de marcadores RAPD. Brasília, Embrapa.

EPAGRI. 2002. Orientações técnicas para a produção de alho em Santa Catarina. 
Florianópolis, Epagri (Série Sistem as de produção).

GI TMANN, L.J. 2004. Princípios de administração financeira. 10ª ed, Upper Saddle River, Prentice Hall, 776 p.

I CEPA. Instituto de Planejamento e Economia Agrícola de Santa Catarina. 2003. Síntese Anual da Agricultura de Santa Catarina - 2002-2003. Florianópolis, I cepa, 285 p.

I CEPA. INSTITUTO DE PLANEJAMENTO E ECONOMIA AGRÍCOLA DE SANTA CATARINA. 1996. Alho. Florianópolis, I cepa, 114 p. (Série Estudo de economia e mercado de produtos agrícolas, 3 ).

KREUZ, C. L. 2003. Análise da competitividade de atividades agrícolas na região de Caçador, Santa Catarina. Florianópolis, Epagri, 52 p. (Série Documentos).

KREUZ, C. L.; LUCINI, M. A.; DALLAMARIA, G. C. M. 1997. Cadeias produtivas do Estado de Santa Catarina: alho. Florianópolis, Epagri, 43 p. (Série Boletim Técnico, 94).

KREUZ, C. L. et al. 2004. Análise de estratégias para os tomaticultores da região de Caçador-SC. In: Congresso Brasileiro de Economia e Sociologia Rural, 17, 2004, Cuiabá. Anais... Cuiabá, Sober, CD- ROM.

SILVA, E. L. e MENEZES, E. M. Metodologia da Pesquisa e Elaboração de Dissertação. Disponível em: http://www.eps.ufs.br, acesso em 18/07/2003, 121 p.

SOUZA, A. KREUZ, C. L; CLEMENTE, A. 2002. Metodologia para análise da viabilidade do cultivo de pinus (Pinus taeda): o caso da região dos Campos de Palmas. Revista de Negócios, 7(4): 51- 62.

SOUZA, A. e CLEMENTE, A. 2004. Decisões financeiras e análise de investimentos. São Paulo, Atlas, 142 p.

VIEIRA, L. M. 2004. SÍNTESE DA AGRICULTURA CATARINENSE-2003-2004 Desempenho da produção vegetal - Alho. Florianópolis, p. 25- 32. 